\title{
The Causal Agent of Fusarium Disease Infested Shallots in Java Islands of Indonesia
}

\author{
Lina Herlina ${ }^{1,1}$, Bonjok Istiaji $^{2}$, and Suryo Wiyono $^{2}$ \\ ${ }^{1}$ ICABIOGRAD, IAARD, Jl. Tentara Pelajar No. 3A Cimanggu - Bogor 16111, West Java, \\ Indonesia \\ ${ }^{2}$ Plant Protection Department, IPB University, Bogor 16620, West Java, Indonesia
}

\begin{abstract}
The success of disease control is largely determined by the validity of information about the type of causal-pathogen. Fusarium oxysporum f. sp. cepae (FOC) was reported to attack shallots and cause leaf twisting disease in Indonesia. We have conducted researches to investigate the causal agent of Fusarium disease and carried out growth tests on nine genotypes of shallots to determine the disease severity and disease indexes, and the correlation between diseases several agronomic traits. Thirty-five strains of Fusarium spp were isolated from wilted shallots tree and bulbs. Based on morphological characterization and rapid test to the isolates, they were identified as $F$ oxysporum, $F$ verticillioides, $F$ solani and $F$ proliferatum. The shallot genotypes that showed a tolerant response to FOC isolates tested were only Sumenep variety. Mentes, Tajuk, Batu Ijo, and Bima Brebes varieties show susceptible response.
\end{abstract}

\section{Introduction}

The main obstacle in shallot production is the disease attack, one of which is tuber basal-rot disease caused by FOC $[1,2]$. The disease can decrease tuber production both in field and in storage warehouse. FOC is reported to cause wilt and basal rot disease in Allium crops such as onions (Allium cepa), garlic (Allium sativum) and red onions (Allium cepa var. ascalonicum). Variation of marks of the disease caused by FOC turned out to be diverse. The fungus is reported to cause leaf twisting disease in onion, as well as on shallots plantations in several locations in Indonesia [2]. FOC also causes rot at the base of the tuber, as well as on garlic bulbs [3].

Limitations of information and research on Fusarium disease in shallots make it difficult to confirm the status of the pathogenic fungus in the field. In nature, pathogenic $F$. oxysporum is reported to have many special forms with different virulence characteristics according to the host it infects $[3,4]$. Therefore, it is possible that $F$. oxysporumf.sp.cepae might have pathogenic races with varying virulence in shallot. Some pathogens have many races, where the difference between one race and another usually involves specific interactions between the pathogenic races of the host plant [4]. Specificity of such interactions can be detected through the specificity of the resulting symptoms. Understanding and knowing of the specific symptoms, especially those caused by

\footnotetext{
${ }^{1}$ Corresponding author: tydars66@gmail.com
} 
pathogenic F.oxysporum on shallot plants are important in the successful control of the disease in the field. The availability of information on the identification of symptoms and the determination of disease severity is yet still indispensable. To date, there is a very limited reference and information for any source of shallot as germplasms which resistant against Fusarium disease. As the increase of the importance of the disease in the field, the study of response genotype of shallot to pathogenic FOC infection becomes important and very relevant to carry out in order to validate or confirm the information of the existence of resistance or tolerant cultivar or a variety of shallots [5].This research is aimed to determine the disease incidence, disease severity, and criteria of resistance to shallots in Indonesia by trying to develop our methods which are compiled based on various reference methods of determining disease scoring developed by other researchers. Also aimed to investigate the several shallots genotype response against several isolates of FOC.

\section{Methodology}

\subsection{Time and Place and Preparation}

The research was conducted at Screen house, Laboratory of Molecular Biology and Laboratory of Microbiology-Center for Biotechnology and Agricultural Genetic Resources at Cikeumeuh-Bogor, and at Plant Clinic- Department of Plant Protection - Bogor Agricultural University from 2017 until 2019. The genotype of shallots as testing material against pathogenic FOC in this study consists nine genotypes i.e. BatuIjo, Bima Brebes, Mentes, Tajuk, Katumi, Biru Lancor, Maja Cipanas,dan Manjung varieties, which are propagated under controlled conditions (in screen house). The type of isolates of pathogenic FOC.

\subsection{Identification of the Causal Agent of Fusarium Disease}

Tubers and shallot plants from the field collection are washed under running tap water. The diseased tissue was surface sterilized with $70 \%$ ethanol, then also in $0.5 \%(\mathrm{v} / \mathrm{v}) \mathrm{NaOCl}$, and finally rinsed with sterile distilled water. Furthermore, it is air-dried on sterile filter paper. The disinfected sections were cut into $5 \mathrm{~mm}$ size, then incubated for 14 days at $25^{\circ} \mathrm{C}$ in selective agar media. Emerging colonies were observed, and the hyphal tips of the colonies were transferred to potato dextrose agar (PDA) to obtain pure isolate culture [6]. Representative isolates were maintained on PDA plants. Macroscopic and microscopic characteristics of the pure cultures were studied and the species were identified using references as mentioned in Edel-Herman and Lecomte [4].

\subsection{Growth Test}

Isolates of pathogenic FOC were rejuvenated in a potato dextrose broth medium (PDB) and shaken on a shaker-machine for 7 days at a rate of $120 \mathrm{rpm}$. The mycelium and spores formed were filtered with 4 layers of Whatman filter paper. The remaining pellets were blended and then suspended into $200 \mathrm{~mL}$ of sterile water and mixed into $1 \mathrm{~kg}$ of sterile soil (soil sterilization is done 2 times in sequence with the autoclave). The soil containing pathogenic FOC was incubated for 4 weeks to obtain chlamydospores. The population density of chlamydospora was calculated by dilution method on PCNB agar medium. The soil containing chlamydospores is stored indoors at $+17^{\circ} \mathrm{C}$ and used as an inoculum source for testing the shallot genotypic response to $F O C$ infection.

Growth tests were carried out in a screen house, with pathogenic inoculation methods referring to [6]. Seedlings in the form of bulbs that were ready for planting (have stored through shelf life of 3 to4months) were sterilized from microbes by surface sterilization 
treatment and soaking treatmentin $55^{\circ} \mathrm{C}$ sterile- water for 20 minutes. The sterilized bulbs were then planted in a $17 \mathrm{~cm}$ diameter plastic pot containing 500 gram a planting medium (already contained inoculum inside; which inoculum concentration already adjust to fit around $1 \times 10^{5}$ chlamydospore per gram of planting medium). Before being planted, the shallot bulb is cut $1 / 3$ of the shoot. During the test, shallot plants were watered every morning, fertilized by NPK $(15: 15: 15)$ twice, at the age of 2 weeks and 4 weeks after planting (MST) at a dose of $1 \mathrm{~g} \mathrm{pot}^{-1}$.

\subsection{Disease Incidence, Disease Severity and Criteria of Resistance}

In accordance with the objective of this study, we tried to develop methods to formulate the index of disease or disease severity. Fusarium disease in shallots has a distinctive characteristic of symptom, known as twisting or "moler", the presence of chlorosis in the leaves and rot in the basal bulbs. These symptoms distinguished it from diseases that attack other plants. Therefore, applying method of scoring according to other plant disease guidelines might not appropriate, because this will lead to improper and less valid interpretations to determine the severity of the disease. Therefore, this study aimed to build more specific reference but still considering scoring methods that have already existed in other plants with other pathogens.

A total of 9 genotypes each consisting of 20 plants were used to determine the Disease Incidence (DI) and Disease Severity Index (DSI). Isolate FOC-1 which selected from the previous works, was used to manual infection in determining this evaluation. Observation of the phenotypic response was carried out on all plants of each variety. This observation aimed to describe the symptoms of the disease in more detail, and based on the observation, we have developed the disease index in order to provide a reference to research practitioners engaged in the cultivation and breeding of shallots, in terms of observing Fusarium disease in the commodity.

The Disease Index determination was developed based on including modifying the disease index developed by [7] which identifies the twisting disease caused by Colletotrichum and Fusarium in Allium cepa sp. In addition, the determination of symptoms for disease scoring is also referred on Fusarium symptoms on Allium sp by [8]; and also referred to the method of determining the scoring of Fusarium disease in banana plants developed by [9].

The following parameters were used to evaluate disease development and expressed as:

(a) $\%$ Disease Incidence $(\%$ DI $)=\frac{\text { Number of symptomatic plants }}{\text { Total number of plants }} \times 100 \%$
(b) Disease Index $=\frac{\text { sum of all numerical ratings }}{\text { Mximum grade (12)x No.of leaves examined }} \times 100$

There were two category for determined the Criteria of Resistance i.e.: Disease Severity Index based on Newly Emerged Buds and Disease Severity Index based on Leaves Symptom. While the criteria of disease resistance was determined according to [8] with modification. The three defining criteria for the disease index are presented in tables 1,2 and 3 . 
Table 1. Disease Severity Index based on newly emerged buds*

\begin{tabular}{|c|l|}
\hline Score & Symptom \\
\hline 1 & No twisting \\
\hline 3 & Somewhat twisting from the neck \\
\hline 5 & Somewhat twisting from the neck with yellowish-green discoloration on leaves \\
\hline 7 & Twisting leaves with little elongation on the neck \\
\hline 9 & Twisting leaves with strong elongation on the neck \\
\hline 12 & Twisting leaves with elongation on the neck and dropping/falling leaves to the soil surface \\
\hline
\end{tabular}

Note: observation carried out at 14DAP (days after planting)

Table 2. Disease Severity Index based on leaf symptom

\begin{tabular}{|c|l|}
\hline Score & Symptom \\
\hline 1 & No chlorosis \\
\hline 3 & The youngest leaves chlorosis \\
\hline 5 & Necrosis on the tip of the leaf \\
\hline 7 & There is an excessive leaf length increase and the color changes to yellow \\
\hline 9 & Leaves dry out \\
\hline 12 & Plant dead. \\
\hline
\end{tabular}

Note: observation carried out at 21DAP (days after planting)

Table 3. Criteria of disease resistance of shallots

\begin{tabular}{|c|c|}
\hline Percentage DSI & Criteria \\
\hline $0 \%$ & Highly resistant \\
\hline $0 \%-10 \%$ & Resistant \\
\hline $10 \%-30 \%$ & Moderately resistant \\
\hline $30 \%-50 \%$ & Susceptible \\
\hline $50 \%-100 \%$ & Very susceptible \\
\hline
\end{tabular}

\subsection{Response of Genotype of Shallot to FOC Isolates (Growth Test)}

In addition to investigate the response of shallots varieties to $F O C$ infections, we also carried out growth- test. Three isolates of FOC i.e.: FOC-1, FOC-2 and FOC-3 and nine genotype of shallots i.e.: Batu Ijo (G-1), Bima Brebes (G-2), Sumenep (G-3), Mentes (G-4), Tajuk (G-5), Katumi (G-6), Biru Lancor (G-7), Maja Cipanas (G- 8), dan Manjung (G-9), were used for this purposes. The experimental design used in present study was factorial design (2 factors: FOC isolates and shallot varieties). Each treatment was designed into 6 replications. Observations on the response of varieties to this type of $F O C$ isolate, crop resistance criteria were determined based on the percentage of Disease Incidence (DI). Resistance criteria are defined as: percentage value of sick plants " $\mathrm{x}$ " then:

$$
\begin{array}{ll}
0 \% & =\text { Highly Resistant } \\
0 \%-10 \% & =\text { Resistant } \\
10 \%-30 \% & =\text { Moderately resistant } \\
30 \%-50 \% & =\text { Susceptible } \\
50 \%-100 \% & =\text { Very Susceptible }
\end{array}
$$

\section{Result and Discussion}

\subsection{Identification of the Causal Agent of Fusarium Disease}

Based on the results of isolation in the field carried out on shallot and tuber plants with wilt symptoms, we obtained thirty-five isolates of Fusarium spp. various (Table 19). Based 
on the identification results of both macro and microscopic characteristics, these isolates have been identified as $F$. oxysporum (FOX) (26 isolates), F. verticillioides (2), F. solani (3) and $F$. proliferatum (4). The resulting colonies varied in color through pigmentation on PDA, including white colonies, white pink and purple and white (Fig. 1 - 5).
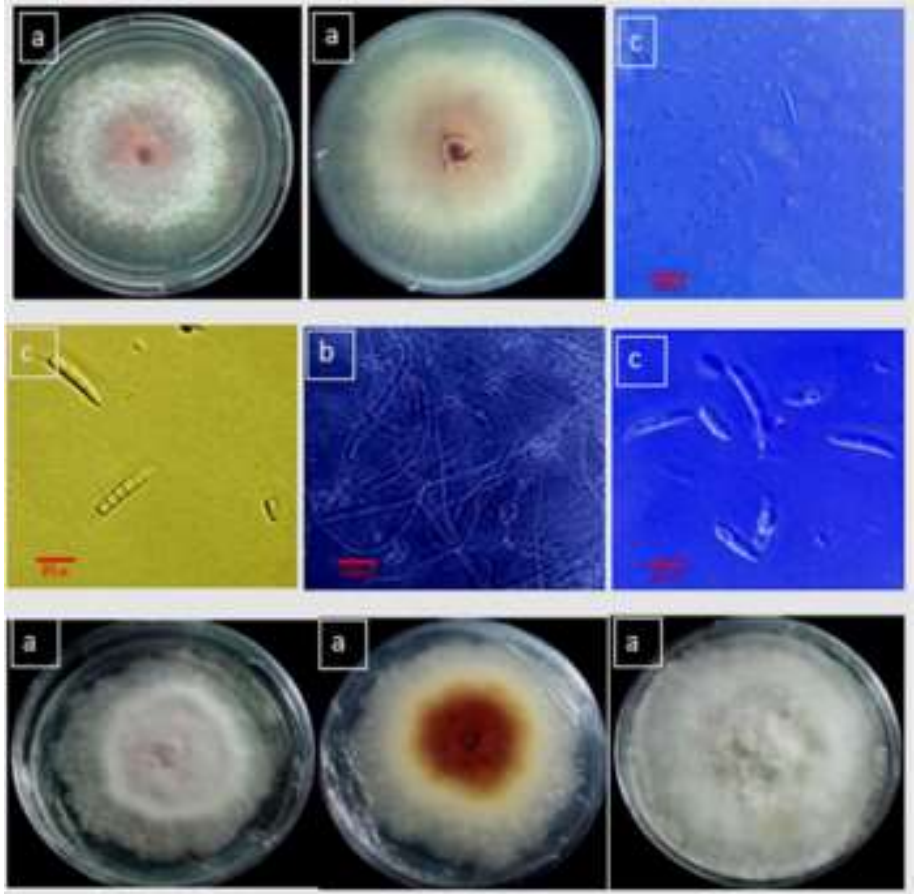

Fig. 1. FOX isolate. (a) Colony pigmentation on PDA, (b) Chlamydospores and (c) Microconidia and macroconidia, size of macroconidia and microconidia, $0.4 \mu \mathrm{m}$ in width
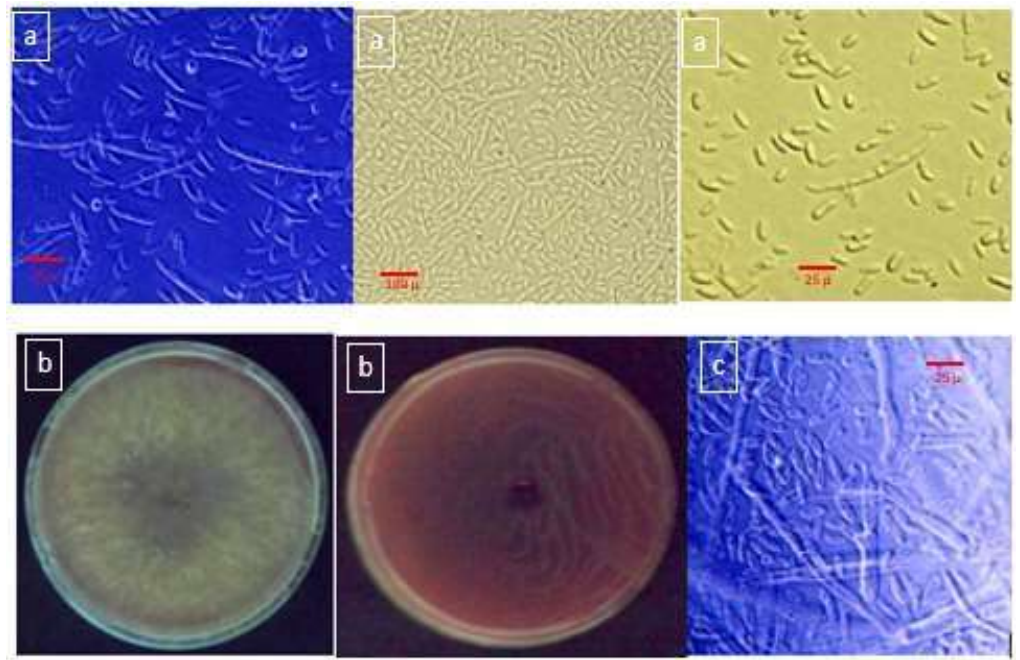

Fig. 2. F verticillioides isolate. (a) Microconidia and macroconidia, (b) Colony pigmentation on PDA, size of macroconidia and microconidia, $0.4 \mu \mathrm{m}$ in width (c) Monophialidic conidiophore and microconidia are abundant

FOX isolates produced white to light violet colonies on pda with aerial mycelia and had 
a cottony or incredibly ropey texture. The shade of the undersurface of the colonies most of the isolates varied from purple or mild to darkish violet or darkish magenta. Microconidia were fashioned in fake heads on quick monophialides uni-orbicellular, and ovoid to ellipsoid microconidia had been considerable. Canoe shaped macroconidia with along apical cellular and a foot fashioned basal cellular shaped $3-5$ septa. Chlamydospores have been typically unmarried or hardly ever in short chains in -week-antique cultures. On a few PDA cultures, macroconidia were comprised of orange sporodochia.
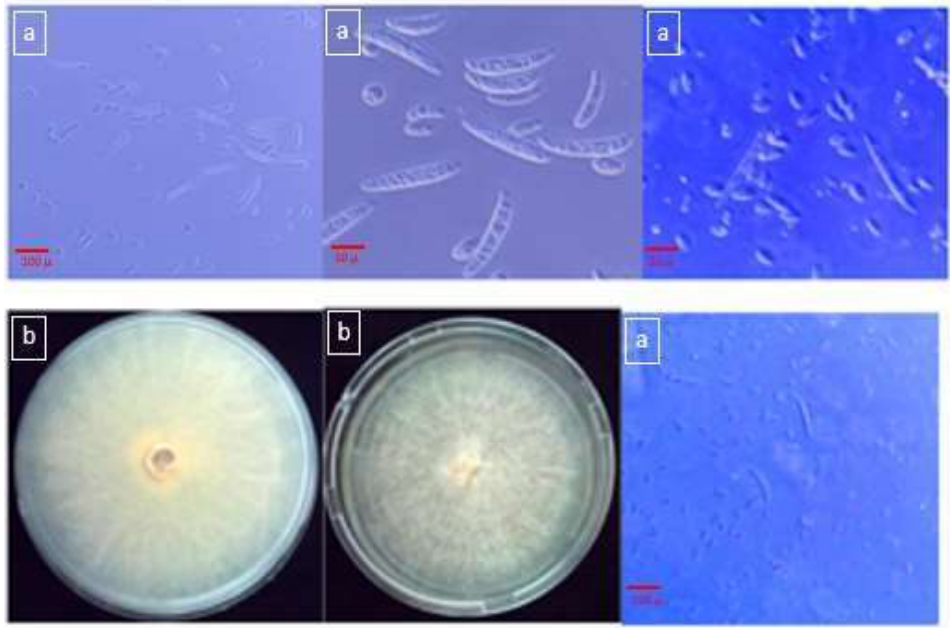

Fig. 3. F solani isolate. a) Microconidia and macroconidia, magnification for both macroconidia and microconidia, $0.4 \mu \mathrm{m}$ in width, (b) Colony pigmentation on PDA

Colonies of $F$. verticillioides on PDA initially produce white mycelia which then turn into dark purple (almost black) pigments with age. Some isolates have violet or pink mycelia, similar to FOX. Microconidia are produced from long unbranched monophialides in long chains in the air mycelium. All isolates of this species produce abundant microconidia which are monocellular and oval or elliptical. The resulting macroconidia are curved, slender, very long and have septa numbering three to five, and apical cells that are curved or tapered. Chlamydospores are absent.

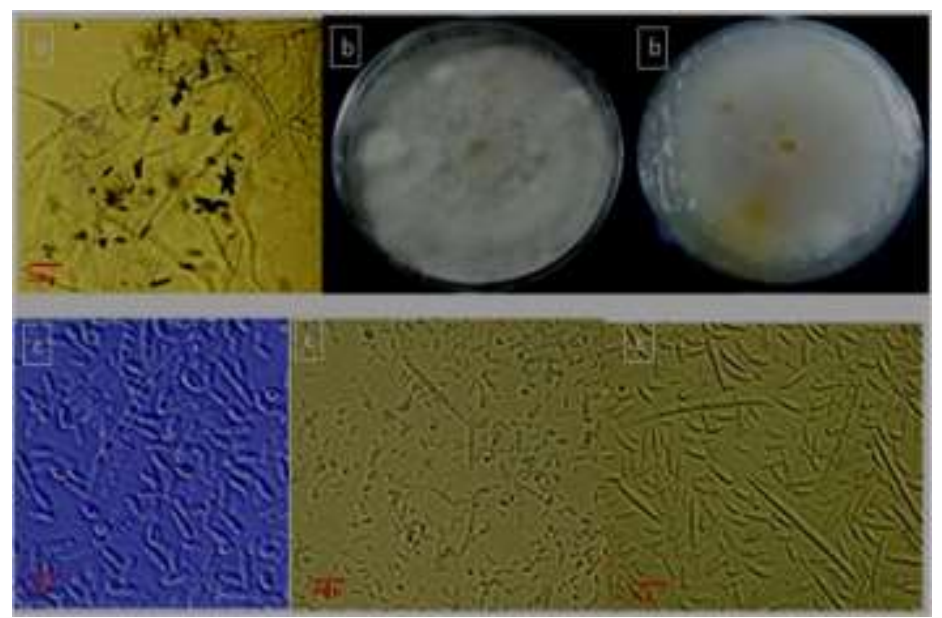

Fig. 4. Fusarium proliferatuvm isolate. (a) Monophialidic conidiophore and microconidia are abundant and (b) Colony pigmentation on PDA, c) Microconidia and macroconidia, size of macroconidia and microconidia, $0.4 \mu \mathrm{m}$ in width 
Fusarium solani isolates on PDA shaped creamy or white colonies, and in some isolates the beneath floor became light violet. The conidia shaped on fake heads on elongated phialides. The oval or elliptical microconidia have been mono- or bicellular. Although macroconidia have been similar to the ones of FOX, they have been wider than the ones of FOX and had a conspicuous wall. Their apical and basal cells have been spherical or footformed and had three or five septa.

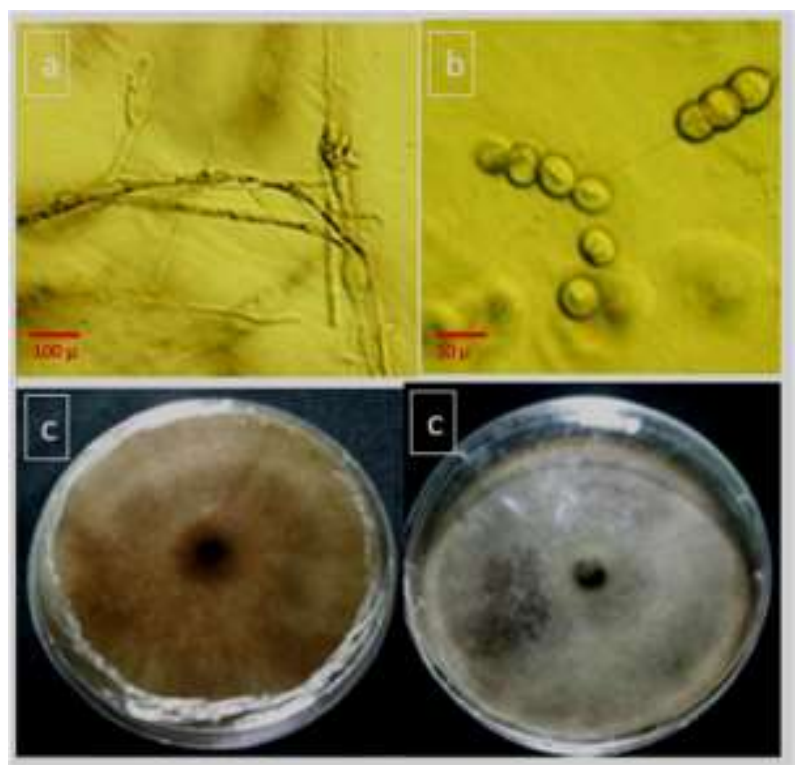

Fig. 5. Fusarium pallidosoreum isolate. a) Monophialidic conidiophore, $0.4 \mu \mathrm{m}$ in width (b) Chlamydospore and (c) Colony pigmentation on PDA

In this study, the results showed that there were various Fusarium species as causal agent of Fusarium disease in shallots, i.e.: Fusarium solani, F. proliferatum, $F$. verticillioides, $F$. pallidiosoreum. For many years, it has been known so far, the only pathogen causing basal rot of tubers in shallot was FOC. Based on the evidence in this study, there is a new fact which become indication that other Fusarium sp also able to cause Fusarium disease in shallot. Furthermore, there also probability that the causal agent of basal rot disease of shallots in Indonesia has undergone a shift, which is not only being monopoly by or specific due to FOC, but also can be caused by other species of Fusarium. To confirm this statement, opportunities for further research are open. The results will be very useful for determining policies and strategies to control this disease in the future.

As comparison, since 2003 it has been reported that $F$ proliferatum become pathogen of onions and garlic plants in North America. As for Italy, F. proliferatum has recently been reported for the first time to cause rot violet basal disease in welsh onion (Allium fistulosum) in 2018 [10]. Although at that time the status was minor-pathogen, but if it is not carefully managed, there is possibility that the pathogen becomes an important one. The case is similar to have happened with $F$ oxysporum f.sp.cepa infected shallots in Indonesia. During 1997 the FOC was known as only a minor pathogen in shallot, but has been changed its status become an important disease since 2007.

\subsection{Response of Shallots Infected by FOC}

All the nine of shallot genotypes-tested showed symptoms of disease, with diverse variations, particularly in their leaves. The first variation was as followed: gradually, at the 
beginning of the infection, the plant shows yellowing leaves from the tip of the leaf to the base of the leaf, where later the leaves become wilted (Figure 6). But there are also those that begin with yellowing from the tip to the base, but after yellowing the next day did not wilt but becomes dry (necrotic dry) (Figure 7).

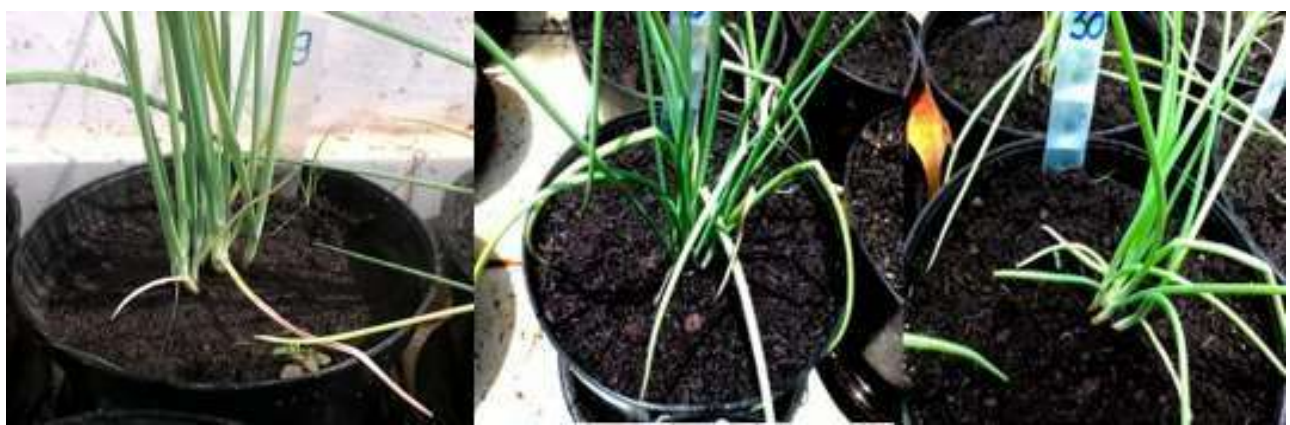

Fig. 6. The shallot's leaves showed yellowing from the tip part to the base part of the leaves, where later the leaves become wilted

In addition, there were also variations of symptoms in the leaf growth. Leaves'length growth abnormally, become much longer, but flat and thick (normal leaves are shaped like a pipe), do not grow upright but wriggle, and the color of leaves is pale green or yellowish (Figure 8). The overall description of this symptom turns out to be in accordance with that reported by [11].

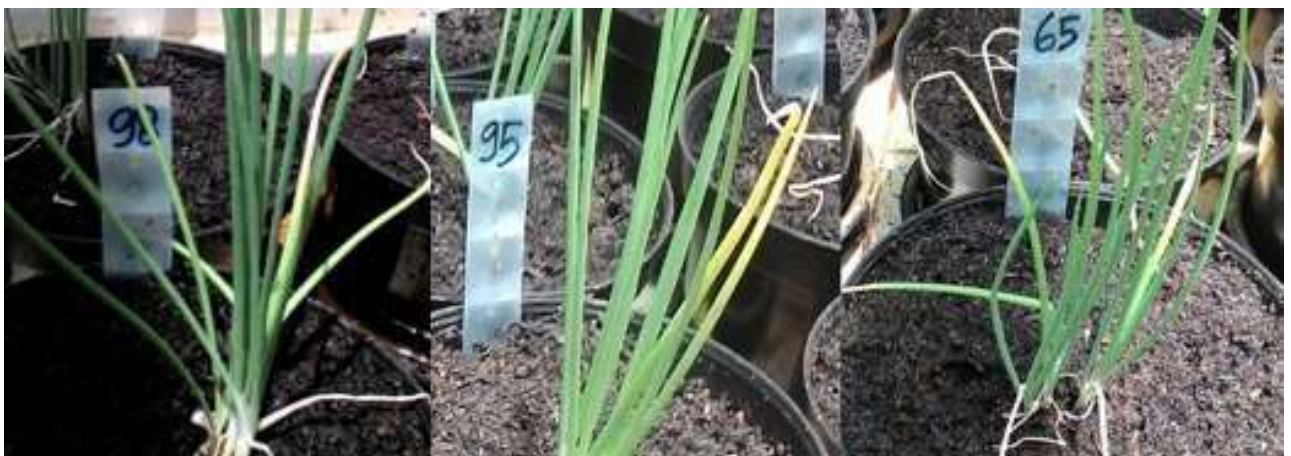

Fig. 7. The shallot-plants shows yellowing from the tip to the base, but after yellowing the next day does not wither but becomes dry

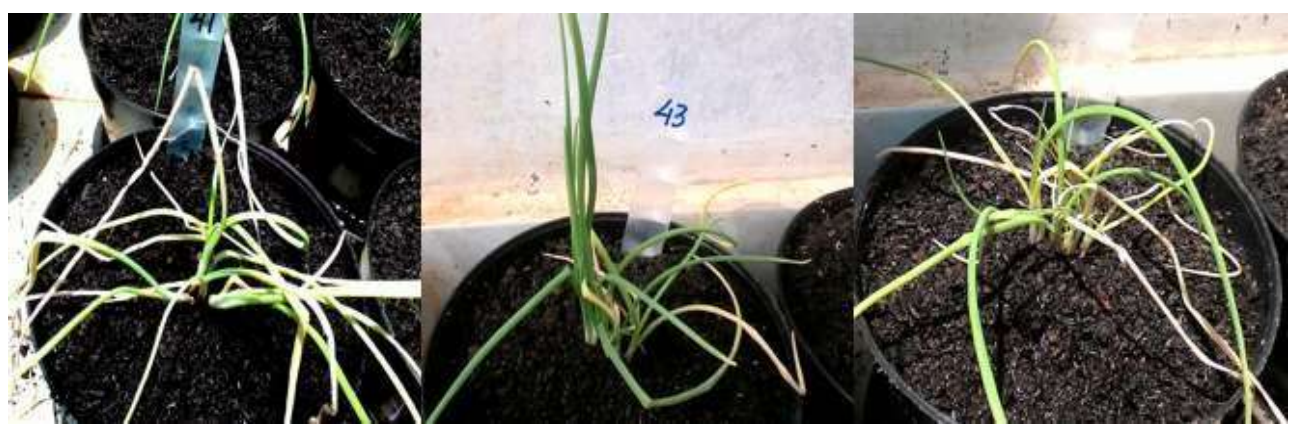

Fig. 8. Shallot's leaves growth longer, become flat and thick, wriggle, and the color of leaves is pale green or yellowish

Advanced symptoms included: plants sometimes become stunted or experience 
excessive growth, in the later stages plants will experience necrosis and bulbs in symptomatic plants will rot. Plant roots are pale brown and are shorter than the roots of healthy plants. In general, symptomatic plants cannot produce tubers or even dry and die. At the level of minor disease attacks the bulbs produced would be smaller and smaller than healthy plants. The result showed, the smallest average percentage of Disease Index was $13.75 \%$ (moderately resistant) obtained by Sumenep genotype, while the most severe obtained by Mentes (75.63\%), Katumi (71.88\%), Tajuk (68.54\%) (Table 24). The other five genotypes were moderately susceptible with percentage of DI within the range of $30 \%$ 55\% i.e.: Batu Ijo, Bima Brebes, Biru Lancor, Maja Cipanas and Manjung respectively (Table 4).

Table 4. Disease Severity Index (\%) based on newly emerged buds and symptom in leaves of shallot

\begin{tabular}{|c|c|c|c|}
\hline Genotype & DSI for newly emerging buds & DSI for leaf symptom & Average \\
\hline G1 & 25.00 & 44.58 & 34.79 \\
\hline G2 & 30.00 & 43.33 & 36.67 \\
\hline G3 & 0.00 & 27.50 & 13.75 \\
\hline G4 & 67.50 & 83.75 & 75.63 \\
\hline G5 & 65.83 & 71.25 & 68.54 \\
\hline G6 & 65.83 & 77.92 & 71.88 \\
\hline G7 & 40.00 & 52.50 & 46.25 \\
\hline G8 & 41.25 & 62.08 & 51.67 \\
\hline G9 & 48.75 & 57.50 & 53.13 \\
\hline
\end{tabular}

The resistance of several shallot varieties to $F O C$ disease also investigated in this study. In order to evaluate and analyze the resistance of shallots against $F O C$ in this study, a method of determining the Disease Index (DI) has been developed. The Disease Index in this study was developed as the improvement or modification from those developed by [7] and [8]. The consideration of developing method for determining the DI was because the symptoms of FOC disease which infested the shallots in Indonesia has specific symptoms and different from FOC strain which were reported from other countries. These differences include symptoms of chlorosis and necrosis as well as twisting leaves in addition to the general symptoms of wilting and rotting of plants. Therefore we assumed that it was necessary to make specific guidelines so that the identification and determination of the severity of this disease could be done more validly.

Based on the observation, none of the nine varieties tested showed resistance to all three FOC isolates. Moderately resistant was obtained by Sumenep genotype.The present study also showed that the symptoms were varied from yellowing,necrotic or wilting leaves,to early death so that at a severe level of attack the plants failed to produce bulb. The present study reported that Sumenep was suggested to be moderately resistant which indicated by the lowest percentage of diseased plants $(\mathrm{DI}=12.20)$ and lowest disease severity (Table 4). This genotype was characterized by the stem with harder tissue structure. It has thicker and piper leaves when it young but then turn-out to be dense, compact, and sturdy clumps. It remained uncertain whether there were relationships between the character of the stem, leaves and roots to the ability of plants to adapt to pathogens. In this case, FOC as a pathogen hemibiotroph, which has the ability to penetrate the plant cell walls to multiply and expand attacks on host plants. The phenotypic response of plants based on observations was also very varied, where when specifically tested using $3 F O C$ isolates it turned out that the influence of isolates, shallot genotype and interaction between genotype and isolate contributed significantly to the symptoms of plant morpho-agronomy. 


\section{Conclusion}

Based on the identification of 35 strains of Fusarium isolates derived from the leaves and tubers of onions, it was found that the isolates consisted of FOX, $F$ verticillioides, $F$ solani and $F$ proliferatum.

Evaluation of the resistance of 9 shallot genotypes to pathogenic FOC shows that only Sumenep varieties have the most tolerant reaction compared to other varieties.

\section{Reference}

1. [Pusdatin- Kementan] Kementerian Pertanian. Kinerja Perdagangan Komoditas Pertanian Vol.6 No.1 Tahun2015.

2. L Herlina, Reflinur, Sobir, A. Maharijaya, S Wiyono, Biodiversitas, 20,3, 696-703 (2019)

3. T.R. Gordon. Annu.Rev. Phytopathol, 55, 23-39 (2017)

4. V. Edel-Herman and C. Lecomte. Phytopathology, 109, 512-530 (2019)

5. L. Herlina and B. Istiaji, Biodiversitas, 21, 10 (2020)

6. Isniah and Widodo, Jurnal Fitopatologi Indonesia,11, 1 (2015)

7. R.T. Alberto. Plant Pathology \& Quarantine, 4,1 (2014)

8. A. Sintayehu, C. Fininsa, S. Ahmed, P.K. Sakhuja. Crop Protection, 30, 1210-1215 (2011)

9. D. Kiswanti, Suryanti, C. Sumardiyono. Jurnal Perlindungan Tanaman Indonesia, 16, 1 (2010)

10. I. Alberti, A. Prodi, M. Montanari, G. Paglia, C. Asioli and P. Nipoti. J of Plant Diseases and Protection, 126, 2 (2018)

11. A. Supriyadi, I. Rochdjatun, S. Djauhari, Jurnal HPT, 1,3 (2013). 